region, and fron: ninety-five measurements of these negatives he has obtained the following values for the relative yearly motion of the Nova in regard to the comparison stars here given :-

$$
\begin{aligned}
& a \text { (B.D. }+43.730) \\
& b(\text { B.D. }+43.732) \\
& c(\text { B.D. }+43.748) \\
& d \text { (B.D. }+43.75 \text { I) }
\end{aligned}
$$

Comparison Star.

$$
\text { Relative yearly motion of Nova. }
$$

$\begin{array}{rlr}\text { In } \overbrace{\text { R.A. }} & & \text { In Decl. } \\ +0.06 & \ldots & \pm 0.05 \\ -0.07 & \ldots & \pm 0.07 \\ 0.00 & \ldots & \pm 0.07 \\ +0.10 & \ldots & \pm 0.02\end{array}$

Herr Bergstrand has obtained $+\mathrm{O}^{\prime \prime} \cdot 033$ as the final value for the absolute parallax of the Nova.

Star with Probable Large Proper Motion.-In making cbservations of Comet $1902 b, \mathrm{M}$. J. Pidoux, of Geneva, has found the position of the star B.D. $-1^{\circ} \cdot 3359$, relative to the position of the star B.D. $-1^{\circ} \cdot 3360$, to be $\Delta a=-0 .^{\circ} 03$ and $\Delta \delta=10^{\prime} 33^{\prime \prime} \cdot 6$. In the catalogue for 1855 , these values are given as $-2 \mathrm{~S} .^{\circ} 4$ and $-12^{\prime} \cdot \mathrm{I}$ respectively, thus showing - if the observations of $\mathbf{M}$. Pidoux are confirmed - that the star has a large proper motion (Astronowische Nachrichten, No. 3834).

Report of the Government Astronomer for Natal, I90I.-This report deals with all the meteorological data collected during I90I at the Government Observatory at Durban and at the thirty subsidiary meteorological stations which are scattered throughout the colony.

The equipment of the observatory has undergone no change during the year.

The table giving the yearly rainfall shows that the amount of rain which fell at Durban during 1901 was considerably above the average, being more than double the quantity recorded during 1900.

Total Eclipse of the Moon, April 22, 1902.--Several series of observations of this eclipse are recorded in this month's Bulletin de la Societé Astronomique de France, and an excellent coloured plate, showing the appearance of the moon at various phases of the eclipse as seen by Dr. W. van der Gracht, of Graz (Styria), accompanies the observations made by him.

\section{THE GREAT IRRIGATION DAM AT ASSUAN.}

THE country of Egypt consisted principally in its natural state of level, arid plains with a few patches of vegetation on the higher parts. Its agricultural prosperity depends entirely on the irrigation derived from the River Nile. It is many thousands of years ago that the first attempt was made to regulate this river and make it serviceable to mankind. In the time of Menes, the west side of the river was embanked, and the water led by a system of canals and embankments to the land lying between the river and the Libyan mountains. When the river was in flood, openings were cut in the banks and the country converted into a series of lakes, the land being enriched and rendered fertile by the warp brought down in suspension by the turbid water of the river. When the floods subsided, the water drained off and the openings made in the banks were again filled up.

This system remained in existence until after the English occupation, when regulating sluices took the place of the more primitive method of cutting and making good the banks. A great depression on the Libyan side of the river was also, in the time of the Pharaohs, converted into a vast regulating basin known as Lake Mæris which was reckoned one of the wonders of the world. Afterwards the right side of the river was also embanked, and the channel enlarged and regulated.

To Joseph of scripture fame belongs the merit of having made one of the principal canals used for irrigating the land, and after the lapse of $40 c 0$ years the Bahr Usuf, or Joseph's waterway, is still doing useful work.

For records of further works of importance, it is necessary to skip over a very long period to the time of Mehemet $\mathrm{Ali}$, about the year 1833, who, under the advice of French engineers, caused to be constructed the great barrage above Cairo across the Rosetta and Damietta branches of the Nile, and, by thus holding up the water when plentiful, a very large area of land is irrigated and rendered highly fertile during the dry period. When the difficulty and cost of obtaining the stone necessary for this great work was pointed out to the Egyptian ruler, it is said he at once gave orders for the destruction of so many of the pyramics as would provide the necessary material, and these monuments were only preserved by the engineers assuring the Khedive that the cost of this would be greater than transporting the stone from other places. Until the English occupation, this barrage was more or less a failure, as, owing to defective foundations, the water could not be held up sufficiently high to make the irrigation effective as it otherwise would be. When the English Irrigation Department obtained control over the works, this defect was with great skill and difficulty remedied.

It has long been recognised by the English irrigation engineers that the present system of irrigation very imperfectly makes use of the fertile properties of the Nile floods. The most perfectly irrigated lands command a rent equal to $5 l$. an acre; imperfectly irrigated land is not worth more than $\mathrm{i} l$. an acre, while one-third of Egypt, or about two million acres, is yet undeveloped. It is estimated that the rental value of Egypt may be increased six millions a year by an effective system of irrigation. The great bulk of the land is dealt with by the original plan of basin irrigation, where the water is carried on to the land during the Nile floods and after remaining there for about six weeks is drained off. The more effective and profitable plan is where perennial irrigation is carried on, that is, where water can be supplied, not only in times of flood, but in summer and dry seasons. To effect this it becomes necessary to store up the water in floods in impounding reservoirs and let it out as required in the dry season.

The great dam at Assuan, which was opened with much ceremony in the presence of the Duke and Duchess of Connaught and the Khedive at the beginning of December, has been constructed for this purpose. This dam, erected across the Nile, will hold up the water for a distance of 147 miles.

For several years, the staff of the English Irrigation Department was engaged in surveying the country in order to arrive at the best site for the intended reservoir, and finally it was decided that the first cataract at Assuan offered the most eligible conditions for this purpose. A scheme designed by Mr. Wilcocks, the chief of the Engineering Department, was approved. This scheme was opposed because the Temple of Philæ would be submerged, and ultimately, in deference to the objections of archæologists and the foreign members of the International Commission who had to be consulted, a compromise was arrived at and the height of the dam was reduced, allowing the temple to stand out above the level of the water. The dam has, however, been so designed that at any future time the additional height can be added to it so as to take full advantage of the natural reservoir capacity. When this is done, ten millions of rental will be added to the resources of the country at a cost of about a quarter of a million a money.

The great dam is a Cyclopæan work. It is a mile and a quarter long, constructed of solid granite and cement, and is founded on the natural bed of granite over which the river runs. The height is 82 feet, and when full it will have a head of 65 feet of water against it. The base is 80 feet and the top 24 feet wide. It is pierced by 140 lower openings $23 \frac{1}{2}$ feet high by 6 feet wide, and 40 upper openings. These openings are provided by doors so hung and balanced that they can be lifted and lowered with very little labour. Through these openings, the Nile water will flow in floods and the scour will carry with it the sediment that may have settled when the water is still. As the flood waters decrease, the doors will be closed and the water impounded and only allowed to escape in such quantities as will be required for irrigation during the summer months. For the navigation, a canal a mile long has been cut through the rocks with a width of 50 feet, and a lock constructed having a descent of 69 feet in four drops.

For the further regulation of the water, another dam has been constructed across the Nile 330 miles lower down, above the entrance to the Ibrahimeh Canal at Assiout, to control the irrigation below this point. Here also a lock has been made of sufficient size to allow the largest steamers using the Nile to pass through.

When this scheme of irrigation was ripe for commencement, a question arose as to how the large sum of money required for its execution were to be raised. The International Commission charged with the finances of Egypt refused to allow a charge to be made on the public debt, and without this per- 
mission the resources of Egypt were not equal to finding the money. In these circumstances, English enterprise came to the rescue. Sir Ernest Cassel, backed by a financial syndicate, undertook to find the money and Sir John Aird contracted to carry out the work. The capital fund is to be repaid by instalments of $166,000 l$. extending over thirty years, and it is anticipated that the irrigation will produce a revenue of $400,000 l$. a year. Sir Benjamin Baker has been the consulting engineer, and the work was carried out under the direction of $\mathrm{Mr}$. Fitzmaurice, lately appointed engineer of the London County Council. The dam has thus been entirely carried out by English enterprise and English capital.

\section{THE VELOCITY OF PROPAGATION OF $X \cdot R A Y S$.} M. R. BLONDLOT has recently made an experimental a result of which he finds that they travel with the same velocity as light. The full account of the work is published in the Comptes rendus for October 27 and November 3 and 10 (vol, cxxxv. pp. 666,721 and 763), and a translation of the first two papers is given in the Electrician for November $2 \mathrm{I}$. As the subject is one of great importance, the following brief abstract of the methods used and the results obtained may be of interest to the readers of NATURE.

The method is based on a principle similar to that of Römer's method of determining the velocity of light. The arrangement of the apparatus is shown diagrammatically in Fig. I. B and B'

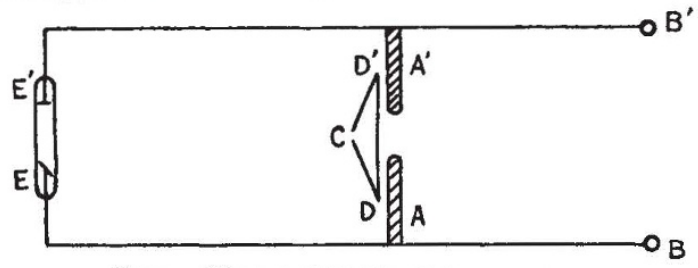

FIG. x.-Diagram of M. Blondlot's appxratus.

represent the terminals of the secondary of an induction coil which are connected to the poles $\mathrm{A}, \mathrm{A}^{\prime}$ of a Hert $z$ radiator and to the electrodes $\mathrm{E}, \mathrm{E}^{\prime}$ of an X-ray tube. Beneath the Hertz radiator is placed a resonator consisting of a copper wire folded into the shape of a triangle $\mathrm{DD}^{\prime} \mathrm{C}$. The spark gap, $\mathrm{C}$, of this resonator is so placed that it receives the X-rays from the focus tube, but is protected from all other radiation by screens of black paper and an aluminium plate. The oscillator $\mathbf{A A}^{\prime}$ consists of two brass cylinders arranged horizontally in a bottle of vaseline oil. By suitably altering the length of the spark gap, the oscil. lator and the focus tube can be made to work simultaneously. The action is then as follows:- At each current of break, the potential between $\mathrm{E}$ and $\mathrm{E}^{\prime}$ rises sufficiently for the X-ray tube to respond. As the potential continues to rise, a spark passes in the oscillator, and this, withdrawing energy from the focus tube, extinguishes it. By careful adjustment, the spark potential of the exciter can be made only slightly greater than the potential necessary to work the tube, in which case the tube will be extinguished very soon after the beginning of the oscillatory discharge, at the end of a time less than a quarter of the period of the radiator. The electric force at the resonator gap only reaches its maximum after a time equal to half the period of the oscillator; hence if the X-ray tube is close to the gap, the Xrays having been extinguished prior to this, there can be no action of the tube on the secondary spark. This conclusion is verified by interposing a sheet of lead between tube and gap, when it is found that the spark is not affected.

Now let the focus tube be kept in the same position and the wires $A E$ and $A^{\prime} E^{\prime}$ be lengthened each by the same amount. This has the effect of delaying the extinction of the tube by the time required for the Hertzian waves to traverse this extra length of wire, and consequently the disappearance of the X-rays at the spark gap C is delayed by the same amount. The X-rays can, therefore, act upon the spark, and that they do so is shown by the fact that the interposition of a lead sheet now makes the spark less bright. If, on the other hand, the wires $\mathrm{AE}$ and $\mathrm{A}^{\prime} \mathrm{E}^{\prime}$ are kept of constant length and the tube moved farther away from the gap, then the X-rays will experience a retardation equal to the time they take to travel from the tube to the gap.
The effect of moving the tube farther off should, therefore, be the same as that of lengthening the wires, and this is again confirmed by experiment; the spark grows brighter as the tube is moved away, but if a lead sheet be interposed, the brightness is unaffected by moving the tube. For a certain distance between tube and gap, the $\mathrm{X}$-rays will have at the gap their full intensity during the whole of the time the potential at the gap has an appreciable value; at this point their effect is a maximum, for increasing the distance diminishes their intensity without increasing the time during which they and the electric force act together at the gap. This position of maximum can be found by experiment.

Let $\mathrm{V}$ and $\mathrm{v}^{\prime}$ be the rates of propagation in centimetres per second of the Hertzian waves and the $\mathrm{X}$-rays respectively, and after determining the position of the tube giving the maximum spark when the connecting wires $\mathrm{AE}$ and $\mathrm{A}^{\prime} \mathrm{E}^{\prime}$ are of given length, let these wires be lengthened by $\alpha \mathrm{cm}$. The cessation of $\mathrm{X}$-rays at the gap is thus retarded by $\alpha / \mathrm{v}$ seconds. In order to re-establish the coincidence of the times and to find the new maximum, the tube must be moved nearer to the gap by a length $\beta \mathrm{cm}$., such that $\beta / \mathrm{v}^{\prime}=\alpha / \mathrm{v}$. The experiment gives $\beta / \alpha$, and therefore $\mathrm{v}^{\prime} / \mathrm{v}$. The following table gives the results of $a$ series of experiments, the first column giving the values of $a$, the second and third columns the values of $\beta$ as determined by M. Blondlot himself and his assistant, M. Virtz, respectively, and the fourth column the mean of these two values. Each of the numbers in columns 2 and 3 is the mean of five determinations.

\begin{tabular}{|c|c|c|c|}
\hline \multirow{2}{*}{$a$} & \multicolumn{3}{|c|}{$\beta$} \\
\hline & Blondlot. & Virtz. & Mean. \\
\hline-7 & -5.9 & -6.5 & -6.2 \\
\hline 9 & 10.5 & 8.9 & $9 \cdot 7$ \\
\hline 12.5 & 12 & 126 & $12 \cdot 3$ \\
\hline 15 & $15^{\circ} \mathrm{I}$ & 14.5 & 14.8 \\
\hline 25 & $25 \cdot 3$ & $24 \cdot 5$ & 249 \\
\hline 30 & 31 & 30 & 30.5 \\
\hline 40 & $39 \cdot 3$ & $39 \cdot 6$ & $39^{\circ} 4$ \\
\hline 25 & $24^{\circ} 6$ & 23.2 & $23^{\circ} 9$ \\
\hline
\end{tabular}

The mean result of all the experiments in this and other series gives the value $0^{\circ} 97$ for the ratio $v^{\prime} / v$.

A variation of the method was also tried in which the ends of the resonator were separated by $0^{\prime} 3 \mathrm{~cm}$., and two wires soldered to them and connected to a micrometer spark gap. These wires were bent back on themselves so as to bring the new gap into the same position as the old one. The Hertz waves have to traverse these wires before producing the spark, and if each wire is lengthened by $a \mathrm{~cm}$., the spark is retarded by $a / \mathrm{v}$ seconds. To obtain the new maximum, the tube must be moved away from the gap by a distance $b \mathrm{~cm}$. such that $b / \mathrm{v}^{\prime}=a / \mathrm{v}$. A number of very concordant experiments by this method gave a mean value 0.93 for the ratio $v^{\prime} / v$.

The final result of all the experiments, therefore, leads to the conclusion that the velocity of propagation of X-rays is equal to that of Herlzian waves or of light through the air. M. Blondlot concludes his papers by pointing out that this conclusion is in harmony either with the hypothesis that $\mathrm{X}$-rays are radiations of very short wave-length or with that of $\mathrm{E}$. Wiechert and Sir George Stokes, that they are electromagnetic impulses produced by the impact between the molecules or electrons in the kathode stream and the antikathode. The fact brought out by these experiments that the X-rays cease simultaneously with the current traversing the Crookes' tube, also supports the latter hypothesis. MAURICE SOLOMON.

\section{RECENT DIETARY STUDIES.}

THE character of the daily menu is influenced by various considerations, but it will be universally conceded that the idiosyncrasies of the palate play the predominant part, and to sug. gest to the ordinary housekeeper that scientific principles should be allowed a voice in the determination of our diet would be simply to court ridicule, for of all departments of the household the kitchen is probably the most conservative in its customs and the most dominated by habit and tradition. It will not be 